\title{
The Effect of Applying the Organization Enterprise Resource Planning System (ERP) in the Quality of Internal Audit: A Case of Jordanian Commercial Banks
}

\author{
Ziad Abdul Halim AL Theebeh ${ }^{1}$, Tareq Hammad AL-Mubaydeen ${ }^{1} \&$ Mahmoud Fawzi Ismael $^{2}$ \\ ${ }^{1}$ Zarqa University, Jordan \\ ${ }^{2}$ Researcher, Jordan \\ Correspondence: Ziad Abdul Halim AL Theebeh, Associate Professor, Zarqa University, Jordan.
}

Received: February 7, 2018

Accepted: March 8, 2018

Online Published: March 25, 2018

doi:10.5539/ijef.v10n5p96

URL: https://doi.org/10.5539/ijef.v10n5p96

\begin{abstract}
This study aimed at examining the impact of the ERP system on the quality of internal auditing in the Jordanian commercial banks. For this purpose, the researchers designed a questionnaire that was distributed to specialists in the same field of this research. The questionnaire consisted of eight perspectives. The study's sample included 21 Jordanian banks, while the study's sample consisted of thirteen Jordanian commercial banks. The results discovered a statistical and significant impact on the application of the organization's resource planning system, especially in the field of finance, marketing, sales, management, human resources as well as the services' system. Based on these results, the researchers raised up a set of recommendations, which are including the necessity of developing the capabilities of the internal auditors in the use of the organization's ERP system in general, and enhancing the accounting system to increase the confidence and the quality of the financial reports particularly. Additionally, it is necessary to explain for the internal auditors the risks, which are embedded in the system of information technology.
\end{abstract}

Keywords: enterprise resource planning, internal audit quality

\section{Introduction}

In order to cope with the development of the rapid changing world, there was a need to develop specified software that will be capable to achieve all the functions in the perspective of the accounting vision. The outcome was summarized in developing what is known as the Enterprise Resource Planning (ERP). Actually, this increasing development of information technology, has led to some new concerns relating to asset security, protection and the credibility of the financial reports, which are submitted to the internal and external entities. These entities have increased the attention as well as concentration on the internal audit, as it is considered as a tool of asset security. Hence the primary aim of this research is to search for the effect of applying the ERP system in the quality of internal audit.

\section{The Study Problem and Questions}

Due to the intensive changes in the work environment as well as the high level of competition; the organizations started thinking of adopting a modern information system that is suitable for fulfilling the internal processes and auditing in these organizations. The result was dealing with what is known as the ERP system. Hence, the study tries to explain the impact of the implementation of the ERP's elements on the quality of the internal auditing in the Jordanian commercial banks. The study will also clarify the impact of the ERP system in the quality of the internal audit from the perspective of the internal auditors, who are working in the commercial banks of Jordan. This study will be conducted based on answering the following core enquiry:

What is the impact of applying the elements of the ERP system on the quality of the internal auditing in the commercial banks of Jordan? This question split into the following sub-questions:

a) What is the impact of applying the accounting system on the quality of the internal auditing in the Jordanian commercial banks?

b) What is the effect of implementing the finance system on the quality of the internal auditing in the Jordanian commercial banks? 
c) What is the effect of applying the marketing system on the quality of the internal auditing in the Jordanian commercial banks?

d) What is the impact of the usage of the sales system on the quality of the internal auditing in the Jordanian commercial banks?

e) What is the effect of the management system on the quality of the internal auditing in the Jordanian commercial banks?

f) What is the impact of the HR system on the quality of the internal auditing in the Jordanian commercial banks?

g) What is the influence of employing of the service system on the quality of the internal auditing in the Jordanian commercial banks?

\section{Objectives of the Study}

This study is conducting for the aim of achieving the following central objectives:

1) Explaining the impact of applying the elements of the ERP system on the quality of the internal auditing in the Jordanian commercial banks.

2) Elaborating the objectives, importance, advantages and disadvantages of applying the elements of the ERP in the Jordanian commercial banks.

3) Explaining the ways of selecting the organization's resource planning system and its construction in the Jordanian commercial banks.

4) Understanding the concept and determinants of the quality of the internal auditing in the Jordanian commercial banks.

\section{The Study Significance}

The importance of this research is to explore the impact of implementing the elements of the ERP on the quality of the internal auditing, in the Jordanian commercial banks. Thus, the significance of this study comes out from its attempts to raise the awareness among the management and the internal auditors regarding the impact of the elements of the ERP system on the quality of the internal auditing in the Jordanian commercial banks. Providing a database based on a personal experience component that is estimated to help the process of making decisions for all administrative levels accurately and efficiently. And eventually, explaining the significance of using the ERP elements in the internal auditing in the Jordanian banking sector.

\section{The Study Model}

In order to achieve the purpose of this study as well as attaining its central objectives; the researchers focused on designed this model to see whether or not the independent variable affecting the dependent variable. The model to be tested is explained as follows:

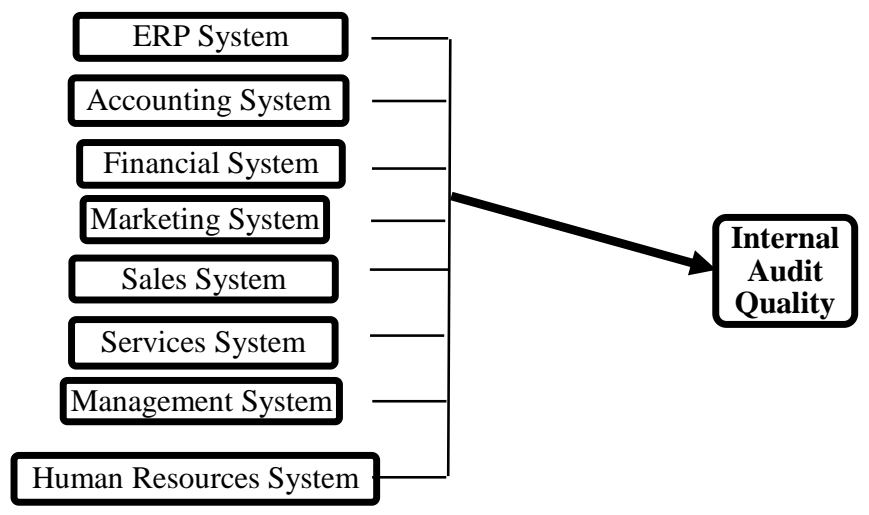

Figure 1. The study's model

\section{The Study Hypotheses}

Based on the study problem as well as objectives; the researchers are trying to test the following main as well as sub hypotheses: 
$\mathbf{H}_{\mathbf{0}}$ : There is no statistical impact to the implementation of the elements of the ERP system on the quality of the internal auditing in the Jordanian commercial banks.

This hypothesis is divided to the following sub-assumptions:

$\mathbf{H}_{\mathbf{0 1}}$ : There is no statistical influence to the accounting system on the quality of the internal auditing in the Jordanian commercial banks.

$\mathbf{H}_{02}$ : There is no statistical effect to the financing system on the quality of the internal auditing in the Jordanian commercial banks.

$\mathbf{H}_{\mathbf{0 3}}$ : There is no statistical effect to the marketing system on the quality of the internal auditing in the Jordanian commercial banks.

$\mathbf{H}_{\mathbf{0 4}}$ : There is no statistical effect to the sales system on the quality of the internal auditing in the Jordanian commercial banks.

$\mathbf{H}_{05}$ : There is no statistical effect to the management system on the quality of the internal auditing in the Jordanian commercial banks.

$\mathbf{H}_{\mathbf{0 6}}$ : There is no statistical impact of the HR system on the quality of the internal auditing in the Jordanian commercial banks.

$\mathbf{H}_{\mathbf{0 7}}$ : There is no statistical effect of the services' system on the quality of the internal auditing in the Jordanian commercial banks.

\section{The Study Variables}

\subsection{Enterprise Resource Planning (ERP)}

It is defined as a system integrates business management and the management system, along with the areas of financial management, transportation, shipping, manufacturing, human resources, and the extended supply chain operations. This system includes the following subsystems, which are operating in an integrated manner (e.g. Accounting, finance, marketing, sales, management, human resources, and services) (Beheshti \& Cyrus, 2010).

\subsection{The Quality of the Internal Audit}

It is defined as compliance with the internal auditing standards, professional codes of conduct, while performing the auditing function, as well as ensuring compliance with the specific policies, and procedures. Additionally, it is established to achieve the performance that is required by the internal audit, in accordance with the auditing standards (Abdali, 2012, p. 11).

\subsection{Enterprise Resource Planning System}

The Enterprise Resource Planning (ERP) system aims at assisting the management through identifying suitable business practices, and providing the management with sound information for timely decision making. The ERP systems are designed to improve all aspects of key operations across the company's entire back office from planning to implementation management, and control as well. These systems achieve their aims through capturing operations and functions that were sporadic, fragmented in the past to be integrated and coordinated in a centralized database. Consequently, the organized resource-planning systems contribute in facilitating day-to-day tasks as well as reducing redundant activities that are supposed to consume time and money as well (Hassan, 2010).

\section{- $\quad$ The Definition of the ERP System}

There are a number of definitions for the ERP system. These definitions are including the following:

1) "It is defined as configurable, ready-to-use software that integrates information and procedures at the level of the functions and departments of the enterprise, regardless of its geography. So that it can use its information, material and human resources effectively and efficiently, easily through providing a comprehensive and integrated solution to the information, which are supposed to be used by the enterprise" (Faoury, 2012).

2) It is also defined as a system managed in a database for a variety of operational functions, such as manufacturing tasks, financial supply management, projects, human resources, and customer relationship management (Al-Majzoub, 2012).

3) It could be also known as an integrated computer-based system that is used to manage internal and external resources. These resources are normally including, physical assets, financial resources, materials and human resources. The ERP system is an integration of operations into a single system and across the organization's system environment (Awheda, 2012). Moreover, from the previous definitions, the researchers concluded that the 
ERP system can be defined as a set of integrated systems, interacting with each other in a base that contributes primarily to the preservation of the organization's resources. These resources can be physical or human resources, and they are normally used effectively and efficiently in order to achieve the objectives of the organization in less time, effort as well as cost.

\section{- $\quad$ Elements of the Resource Planning System}

Although the beginning of the ERP system was limited to industrial environments, however, enterprise resource planning software solutions cover all essential work in the organization (process/task), regardless of the nature of the organization's work. The organization's resource planning programs seek to streamline processes and integrate them into the organization, especially within three components. These components are including Production, Finance, and Human Resources using a unified database to store data for various units of the system (Al-Majzoub, 2012). Al-Faoury (2012) believes that the Organization's Enterprise Resource Planning (ERP) program includes systems for processing operations, which are including actions in the organization's environment and affect their progress towards achieving their objectives. The processes are handled by the system including sales and purchase, invoicing and receipt. However, the researchers believe that there are several types of enterprise resource planning programs, those are serving different types of businesses. These solutions or programs achieve a number of benefits depending on the type of business they serve, such as finance, communications, education, and health care.

The Main Elements of the ERP System are: Accounting System; Funding system; Marketing System; Sales System; Human Resources System; Management System; System services.

\section{- The Objectives of the Organization's Resource Planning System}

1) To ensure an integrated environment that is available in a timely manner and is accurate to all parties, regardless of their locations (Hassan, 2010). Barakat (2011) adds to the current objectives of the organization's resource planning system the set of the following objectives:

2) Assisting the management and the organization's decision makers with sound information in a timely manner.

3) Facilitating the flow of information among all administrative units within the organization.

4) Improving the performance of organizations' operations as well as making them more reliable, less expensive, more responsive, and more capable to achieve the targeted goals.

Therefore, the researchers believe that the system's objectives seek to achieve the objectives of the organization as well as ensuring the good performance of the organization's staff, and making the requested decision perfectly.

\section{- $\quad$ The Advantages of the ERP system}

The advantages, which are offered by the ERP system, are explained as follows (Hassan, 2011):

1) Saving money: Because all the associated programs are integrated into one integrated system, and minimizing the use of machines and servers, which also means savings human resources.

2) Productivity improvement: The system reduces the default time of each production process, which increases the speed of the project's completion.

3) Facilitating the management of daily operations: All data is placed in one place, which in turn leading to eases the process of completing the daily duties as well as facilitating the process of storing all the data.

4) Improving the strategic planning in the enterprise: It is easy to store all the variables in the system. For example costs, graphs, resources and others, which facilitates planning and construction in a manner appropriate to the company. Additionally, there are some other advantages that the organization derives from using the resource planning system. These advantages are summarized in the following:

a. The system deals with one database

b. Providing accurate information to management and different organizational levels in the organization, as well as to customers, and suppliers.

c. The system provides the possibility of sharing data and information, and obtaining it regardless of its source (Al-Majzoub, 2012).

Through what was discussed above, the researchers believe that the emergence of the organization's resource planning system has created a number of advantages, which in turn led to increase the efficiency and 
effectiveness of business processes within the organization. In addition, this system is compatible with business processes within the organization.

\subsection{Auditing Quality}

The quality has become required in various areas of professional work. However, it did not show a clear and comprehensive concept and definition of quality in the review, due to considering from the different perspectives (Al-abdali, 2012).

The quality of the internal auditing reflects on the characteristics, which must be gained by the accounting information. The determination of the whole range of accounting information's features contribute in assisting the preparers of the accounting standards as well as assisting those, who are responsible to prepare the financial statements in assessing the accounting information (Ismail \& Naoum, 2013, p. 289). The quality of the internal audit is performed after the accounting process will be performed. The discovery of errors, fraud and accounting data is the primary function of the internal auditor, namely, the verification of the integrity of the records, data and the preservation of the assets of the organization. As an inevitable result of the technological development, and to assist management in deciding how to implement the various activities (Al-wardat, 2006).

\subsubsection{The Concept of the Internal Audit's Quality}

Since the concept of the internal auditing quality is relatively a modern concept, it is necessary to focus on this concept as one of the concepts or trends in contemporary auditing. There are a number of definitions for the auditing quality:

1) The ability of auditing to detect the weaknesses in the internal control system, making recommendations to address or reducing them, and maximizing the potential benefit of the client company.

2) Adherence to audit standards and codes of conduct during the audit function (Dardas, 2010)

3) The characteristics of the professional opinion of the auditor that satisfies the needs of users, such as shareholders of the financial statements, within the limits of the practical and economic constraints of the auditing environment (Salem, 2013). The researchers believe that the internal auditing quality is reflected in the characteristics that accounting and financial information must have, which leads to the extraction of correct and non-misleading financial statements that help decision makers and users of these lists and the purpose for which they are found.

\subsubsection{The Quality of Auditing and Accounting Information}

The quality of the internal audit reflects the characteristics that accounting information should have. The determination of the whole range of accounting information features helps accounting standards preparers, assisting those who are responsible to prepare the financial statements to evaluate the accounting information, and determines whether the audit is of quality or not (Al-Mutairi, 2012). The qualitative characteristics of the accounting information are considered the basis of the auditing quality. If the qualitative characteristics are lost, the quality of the auditing will not be achieved (Hamadoun, 2015). Qualitative characteristics are considered one of the qualities that make information in the financial statements useful to users, and the basic qualitative characteristics are explained below (Audeh, 2011):

1). Reliability: It is achieved through fulfilling the following sub-characteristics:

- Verification and completeness, caution, sincerity of presentation (true representation) neutrality free of prejudice (Hamadoun, 2015).

2). Comparability: This feature enables those who are using financial accounting information to identify the real aspects of the similarities and differences between the performance of the establishment and the performance of other entities, over a certain period of time (Awawdah, 2014).

3). Relevance of information: This property relates to the decision makers. Thus, their presence in the accounting information contributes to quality assurance in the audit process to increase their impact on present control and assimilation of the past in order to predict the future objectively, that makes it easier for users of this information to make a decision. That information was inappropriate (Ismail \& Naoum, 2012).

\section{Literature Review}

Barakat study (2011) aimed to determine whether there is actual application of the ERP systems with its components (sales, marketing, management, production, accounting and finance, human resources), and then determine the impact of the application of the ERP systems on the return on investment of the industrial companies, which are listed in the Saudi Stock Exchange. The study concluded that the implementation of the 
ERP components affects the return on investment in the industrial companies, which are listed on the Saudi financial market. The researcher recommended companies, which are not using the resource planning system to implement it in order to improve their financial performance.

However, Kanani (2013) aimed at identifying the impact of the ERP application on the competitive advantages of the pharmaceutical companies in Jordan. The study showed that there is a statistical and significant effect of adopting the application of resources on the cost, quality, flexibility and creativity in pharmaceutical companies in Jordan. Additionally, the study recommended that the pharmaceutical companies should continue to adopt the ERP system, and develop it periodically to meet the requirements of the emerging labor market. It is necessary to work on the continuous updating of databases on materials, human resources, and suppliers in the ERP system, because these rules feed the planning processes as well as analyzing resource's requirements.

Anyway, Al-Jabari (2004), aimed to develop a model for conducting an actual audit under a computer-based accounting system and how to use the computer to support the audit. This study was based on interviews with all auditors at Zain company in Jordan. The study concluded that with the development of a model for conducting an audit within an electronic accounting system. This model proved effective in terms of time taken and reduction of losses because it starts with the risks that are of utmost importance because their importance leads to the loss of the company. And then the activities at each session are identified and the risks of the most important are identified in these activities and then these risks are examined. A research conducted by Yousef and Shatha (2010) aimed at enhancing the awareness of the importance of the critical factors in the success of applying the ERP system in the Jordanian industrial companies that applied the Baan-LN system. The study concluded that there is a relationship between the administrative factors, the organizational structure and the successful implementation of the system.

\section{Methodology and Procedures}

\subsection{Methodology of the Study}

The researcher reviewed the related literature as well as analyzed the information content of the questionnaire, which is distributed to the sample of this study. The study used the descriptive and analytical method through using the statistical method of sampling, because it seems to be important for measuring the reliability and accuracy of the results.

\subsection{Population of the Study}

The study population is consisted of 13 Jordanian commercial banks. The official statistics of this study are obtained from the official records of the Amman Financial Market.

\subsection{Sample of the Study}

To determine the study's sample, all the individuals employed in this research were approved as a sample for this study. The study's sample includes the internal auditors and the employees who are using the ERP system in the Jordanian commercial banks. However, to test the study's hypotheses, a total of 144 questionnaires were distributed to the study's sample. Nevertheless, 129 questionnaires were retrieved, 8 were excluded as they are found to be not valid for the statistical analysis's job. So the total number of the questionnaires, which are analyzed, was 121 . The percentage of the questionnaires, which are found to be valid for the statistical analysis, is $(93.8 \%)$. The following table shows the following:

\subsection{Sources of Data Collection}

The study depends on two main sources of data collection. These sources are:

1)- Secondary sources: the scientific books, previous studies, published researches in periodicals, scientific journals, statistics, and websites dealing with the study's subject.

2)- The primary sources: Based on the design of a questionnaire that is distributed to the study's sample in the Jordanian commercial banks. The style of the five Likert scale was used to determine the importance of each of the sections of the study tool. To confirm the apparent honesty of the tool, the researchers presented the questionnaire to (8) perspectives in the audit system, the organization's resource planning system, and their comments on deletion, addition, or amendments proposed by the larger number of them, and by more than (85\%). To verify the intrinsic integrity of the tool (sincerity of the content), the researchers calculated it by dividing the questionnaire on a sample of 30 individuals and calculating the correlation coefficient between their paragraphs.

\subsection{Statistical Processing}

The following statistical tests have been used: 
1) Descriptive statistics is used to find averages, standard deviations, percentages and grades as well.

2) Multiple-Regression was also used to test the relationship between the independent and the dependent variable.

3) Pearson correlation coefficient was used to confirm instrument stability, and Kronbach-alpha equation to find the coefficient of internal consistency of the used tool (Questionnaire).

4) One sample T-test was used to detect the significance of the differences in the average estimates of the study's sample.

\section{The Results of Descriptive Statistics for the Study's Sample}

$71.1 \%$ of the study sample are found to be individuals with a bachelor's degree, while $20.7 \%$ of the study sample are postgraduate studies, and $42.1 \%$ of the study's sample with academic specialization in accounting, and $40.5 \%$ of the study sample are specialized in finance. Moreover, $32.2 \%$ of the respondents are individuals with a professional certificate of Jordanian Certified Public Accountant (JCPA), and 12.4\% of the respondents are individuals with a Certified Professional Accountant (CPA), in addition, $18.2 \%$ of the respondents are individuals who hold the certificate of Certified Professional Accountant (CMA).

\subsection{Answering the Study Questions and Testing Hypotheses}

The results, which are related to the following main question:

\section{- Is there an ERP Application in Commercial Banks?}

To answer this question, the arithmetical averages, standard deviations, level, and rank of each resource planning system in Jordanian commercial banks were calculated. The study showed that:

1- The mathematical averages and standard deviations for the perspective of (the accounting system in the Jordanian commercial banks):

It is clear that the mean between (4.54-2.76) and that the general average of the dimension reached (3.91) with a standard deviation (0.70). It indicates that the accounting system is applied in Jordanian commercial banks to a high degree and in a manner that guarantees quality in the internal audit process. It provides reliable, convenient, comparable and easy-to-understand information and makes it available for decision making to all the Bank's responsibility centers.

2- Accounting averages and standard deviations for the perspective of (the system of financing in the Jordanian commercial banks):

It is clear that the averages ranged between (4.53 - 3.12) and that the general average of the dimension is (4.22), with a standard deviation (0.68). It indicates that the financing system is applied in the Jordanian commercial banks to a high degree and in a manner that ensures the quality of the internal auditing process, in order to make available data on which the cost of funding can be calculated.

3- Accounting averages and standard deviations for the perspective of (marketing system in the Jordanian commercial banks):

It was found that the averages ranged between 4.27-3.23 and the general average of the dimension reached (3.89), with a standard deviation (0.83). It indicates that the marketing system is applied in the Jordanian commercial banks to a high degree.

4- The averages and standard deviations for the perspective of (the system of sales in Jordanian commercial banks):

It was found that the arithmetical averages ranged from 4.50 to 4.11 and the general mean of the dimension was 4.27 , with a standard deviation of 0.64 . The results found that the sales system is very high in the Jordanian commercial banks.

5- The averages and standard deviations for the perspective of (management system in the Jordanian commercial banks):

The results found that the averages ranged between (4.40-3.98) and the general average is (4.20), with a standard deviation (0.67). the study indicates that the management system is applied in the Jordanian commercial banks to a high degree.

6- The averages and standard deviations for the perspective of (human resources system in the Jordanian commercial banks): 
The study found that the mean ranged between (4.40-3.93) and the general mean is (4.18), with a standard deviation (0.68) indicating a high level.

7- The arithmetical averages and standard deviations for the perspective of (system of services in the Jordanian commercial banks):

The results found that the averages ranged from 4.40 to 3.12 and the general average is found to be 4.01 , with a standard deviation of 0.73 indicating a high level. The results, which are relating to the second question. This question is as stated below:

What is the impact of the application of elements of the ERP system on the quality of the internal auditing in the Jordanian commercial banks?

In order to answer this question, the averages, standard deviations, level, and rank were obtained for the quality of the internal auditing in the Jordanian commercial banks. From the point of view of the study's sample, the results indicated that the arithmetic mean ranged between (4.34-3.12) and the general mean is (3.94), with a standard deviation (0.730.78) indicating a high level.

To answer the sub-questions, the study's tested the following hypothesis:

$\mathbf{H}_{01}$ : There is no statistical impact to the implementation of the elements of the ERP system on the quality of the internal auditing in the Jordanian commercial banks. To test this hypothesis, a simple regression analysis was carried out, and the results are as shown in the following table:

Table 1. The results of the simple regression analysis of the application of the elements of the ERP system on the quality of the internal auditing in the Jordanian commercial banks

\begin{tabular}{ccccc}
\hline Correlation & Coefficient & Beta & F & Sig \\
\hline 0.680 & 0.462 & 0.680 & 102.275 & 0.000 \\
\hline
\end{tabular}

The above table showed the correlation coefficient between the application of the elements of the ERP system and the quality of the internal auditing in the Jordanian commercial banks was 0.680 , and the higher the absolute value of the correlation coefficient, is the stronger the correlation. This correlation enhances the importance of the application of the Organization's resource planning system to improve the quality of internal audit with a 100\% confidence level, over the overall total, and that the value of (F) corresponding to (102.275) is a function at the level of 0.05 and less. This indicates that the regression equation was a good predictor, so there is an impact to apply the elements of the ERP system on the quality of the internal auditing in the Jordanian commercial banks. The study concluded that each element of the ERP system is impacting the quality of the internal auditing in the Jordanian commercial banks is affected. The results of this study agree (Barakat, 2011) as he indicated that there is a positive impact for the implementation of the ERP system on the bank's financial performance.

\section{Results and Recommendations}

\subsection{Results}

1). The implementation of the ERP system in the Jordanian commercial banks leads to improving the quality of the services, which are provided by the bank to the customers, and there is a link between this system and the bank's responsibility centers.

2). The implementation of the ERP system in the Jordanian commercial banks contributes in storing, classifying and registration all transactions in a timely manner. Consequently, that will reduce business risks, which in turn is positively affecting the results of the audit process, which helps to increase the quality of the internal auditing process.

3). The ERP system allows the obligation of applying with the internal and internal regulations and the achievement of the objectives in line with the interest of its employees, in a manner that does not conflict with the interest of the Bank and contributes to make the right decisions that are in the best interest of the Bank.

4). The study found that when applying the ERP system, the auditor design and implement the appropriate control tests and material procedures when using this system in the audit process. It also contributes to the method of selecting the statistical samples in the audit, resulting in additional protection for the internal auditor from risk of issuing an inappropriate opinion, or taking inappropriate action.

5). There is a statistical and significant impact for the application of the ERP system on the quality of the internal auditing in the Jordanian commercial banks. The implementation of this system has a statistical and significant 
effect on the quality of the internal auditing process in the Jordanian commercial banks.

\subsection{Recommendations}

Based on the study results, the researchers raised up the set of the following recommendations:

1). Developing the capabilities of all internal auditors with regard to the use of the accounting system in particular, and the rest of the applied systems in general, in order to enhance confidence and quality in their reports.

2). The internal auditor should know how to design suitable and appropriate IT control tests, such as information security risks, and change their contents.

3). Increasing the interest of the banks in providing training programs in the field of developing the internal auditors' abilities in terms of the permanent control, over the system and its contents in a manner consistent with the modern technical environment.

4). Improving the efficiency of IT staff, and the employees who are concerned with handling the errors resulting from the misuse of the ERP system. Consequently, that will contribute in reducing the potential error rate. Finally, that will positively impacting the quality of the work in general and the quality of the audit in particular.

\section{References}

Abdali, M. (2012). The Effect of Institutional Governance on the Quality of Internal Auditing. Master Thesis, Business School, Middle East University, Amman, Jordan.

Al-Faouri, A. (2012). Effectiveness of Resource Planning Systems on Excellence in Corporate Performance. Master Thesis, Business School, Middle East University, Amman, Jordan.

Al-Majzoub, A. A. (2012). ERP Systems. Al Yamama Library, Riyadh, Saudi Arabia.

Al-Mutairi, F. (2012). The Importance of Information Technology in Audit Quality Control and Constraints of Use from Auditors' Point of View in the State of Kuwait. Master Thesis, Business School, Middle East University, Amman, Jordan.

Al-qadi, H. (2008). Internal Auditing. Damascus, Syria: Damascus University Press.

Awhida, A. (2012). The Importance of Information Management in the Planning of the Organization's Resources. Unpublished Master Thesis, Libyan Academy, Libya.

Barakaat, A. (2011). Measuring the Impact of ERP Application on Return on Investment, Applied Study. University of Alshaqra', Saudi Arabia (International Forum on Intellectual Capital in Arab Business Organizations in Modern Economies).

Beheshti, H. M., \& Cyrus, M. B. (2010). Improving productivity and firm performance with enterprise resource planning. Enterprise Information Systems, 4(4), 445-472. https://doi.org/10.1080/17517575.2010.511276

Dardas, K. W. (2010). The Effect of Internal Audit Service on External Audit Quality in Listed Companies in Amman Stock Exchange. Unpublished Master Thesis, Business School, Jadra University, Irbid, Jordan.

Hassan, S. (2010). Critical Factors in Successful Enterprise Resource Planning Application. Unpublished Master Thesis, Middle East University, Amman, Jordan.

Kanani, R. (2013). The Impact of the ERP Application on Competitive Features. Unpublished Master Thesis, Business School, Amman Arab University, Amman, Jordan.

Mutairi, A. (2012). Code of Conduct and Ethics of Auditing and its Impact on the Quality of the Audit Process in Kuwaiti Industrial Companies. Master Thesis, Faculty of Business, Middle East University, Amman, Jordan.

Yousef, S. H. H. (2010). Critical Successes Factors in Enterprise Resource Planning (ERP) systems implementation. $\mathrm{PhD}$ dissertation, Middle East University.

\section{Copyrights}

Copyright for this article is retained by the author(s), with first publication rights granted to the journal.

This is an open-access article distributed under the terms and conditions of the Creative Commons Attribution license (http://creativecommons.org/licenses/by/4.0/). 